\title{
27-gauge sutureless vitrectomy under topical anesthesia: A pilot study
}

\author{
Joanna Adamiec-Mroczek ${ }^{A-F}$ \\ Department of Ophthalmology, Wroclaw Medical University, Poland \\ A - research concept and design; $B$ - collection and/or assembly of data; $C$ - data analysis and interpretation; \\ $\mathrm{D}$ - writing the article; $\mathrm{E}$ - critical revision of the article; $\mathrm{F}$ - final approval of the article
}

Address for correspondence

Joanna Adamiec-Mroczek

E-mail: joanna.adamiec-mroczek@umed.wroc.pl

Funding sources

None declared

Conflict of interest

None declared

Received on March 29, 2021

Reviewed on May 17, 2021

Accepted on September 17, 2021

Published online on October 5, 2021

Cite as

Adamiec-Mroczek J. 27-gauge sutureless vitrectomy under topical anesthesia: A pilot study. Adv Clin Exp Med. 2021;30(10):1099-1103. doi:10.17219/acem/142353

DOI

10.17219/acem/142353

Copyright

Copyright by Author(s)

This is an article distributed under the terms of the

Creative Commons Attribution 3.0 Unported (CC BY 3.0)

(https://creativecommons.org/licenses/by/3.0/)

\section{Abstract}

Background. The implementation of the 27-gauge (G) sutureless vitrectomy technique is associated with a marked shortening of surgery time, faster healing of scleral and conjunctival wounds, less severe conjunctival scarring, limited postoperative corneal astigmatism, and marked improvement in the postoperative comfort of patients. The traditional methods of anesthesia for vitrectomy surgery are quite varied and each has its own potential for complications.

Objectives. To assess the feasibility and safety of $27 \mathrm{G}$ pars plana vitrectomy (PPV) performed under local topical anesthesia for diabetic maculopathy, asteroid hyalosis and vitreomacular traction syndrome associated with high myopia.

Materials and methods. Three carefully selected patients with various vitreoretinal disorders underwent primary 27G PPV performed by a single surgeon under local topical anesthesia. Patients were analyzed in regard to best corrected visual acuity, intraocular pressure, intraoperative/postoperative complications, intraoperative/postoperative pain, and surgery time.

Results. All patients showed postoperative improvement in visual acuity. No decrease in intraocular pressure below $10 \mathrm{~mm} \mathrm{Hg}$ was documented on postoperative day 1. Furthermore, no postoperative complications were recorded during the six-month follow-up, and evident improvement in the anatomical status was confirmed using ophthalmic coherence tomography in all cases.

Conclusions. Our findings support that 27G PPV performed solely under local topical anesthesia is safe and effective for treating selected vitreoretinal disorders.

Key words: 27-gauge, pars plana vitrectomy, maculopathy, high myopia, local topical anesthesia 


\section{Background}

The implementation of the sutureless vitrectomy technique has revolutionized the work of vitreoretinal surgeons in the last 5 years. The 23- and 25-gauge (G) pars plana vitrectomies (PPV) are performed with increasing frequency and have a well-established position in modern ophthalmology. ${ }^{1}$ Pars plana vitrectomies are associated with a marked shortening of surgical time, faster healing of scleral and conjunctival wounds, less severe conjunctival scarring, limited postoperative corneal astigmatism, marked improvement in postoperative comfort of patients and, in some cases, earlier postoperative visual recovery than after traditional $20 \mathrm{G}$ PPV. ${ }^{1}$

All of these advantages of novel vitreoretinal techniques result from the intraoperative formation of selfsealing scleral incisions; due to their presence, no sutures need to be placed on the sclerectomy and conjunctival wounds. However, the lack of suture placement on $0.6 \mathrm{~mm}$ (23G) or $0.5 \mathrm{~mm}(25 \mathrm{G})$ wounds can quite frequently lead to complications such as hypotony, choroidal detachment and increased risk of exogenous endophthalmitis. ${ }^{2,3}$ The risk of these complications seems reduced in cases in which a $27 \mathrm{G}$ vitrectomy system is used and the diameter of the wounds equals $0.4 \mathrm{~mm}$.

In 2010, Oshima et al. presented a $27 \mathrm{G}$ instrument system successfully used in their center for transconjunctival fluid-air and fluid-fluid exchange. ${ }^{4}$ The limitations of the system - namely the insufficient illumination of the globe and poor performance of the stripper resulting from its small diameter, as well as the excessive flexibility of the instruments - were the main obstacles to the popularization of the $27 \mathrm{G}$ vitrectomy. However, the manufacturers of modern vitrectomy systems have managed to eliminate most of these flaws. ${ }^{5}$

\section{Objectives}

In view of the markedly shorter duration of $27 \mathrm{G} \mathrm{PPV}$ compared to $20 \mathrm{G}$ vitrectomy, we decided to conduct a pilot study of 27G PPV under topical anesthesia in a carefully selected group of patients. We chose this model of anesthesia because it is safe and eliminates the postoperative discomfort associated with periocular anesthesia.

\section{Materials and methods}

All patients provided written informed consent prior to their inclusion in this study.

The 27G PPV involved 3 phakic globes of patients with diabetic maculopathy resulting from proliferative diabetic retinopathy $(\mathrm{n}=1)$, asteroid hyalosis $(\mathrm{n}=1)$ and vitreomacular traction syndrome associated with high myopia $(n=1)$. All patients were free from degenerative disorders of the spine and hips, dementia, asthma, chronic bronchitis, and deafness. Patients' ability to cooperate with the surgeon performing PPV was verified by means of ophthalmoscopy and ophthalmic coherence tomography (OCT) during qualification for the procedure. All patients were informed that they would experience a sensation of touch and that the movements of the operated globe would be retained throughout the surgery.

After achieving maximal mydriasis with $1 \%$ tropicamide and $5 \%$ phenylephrine, all patients received topical anesthesia with 5 drops of proxymetacaine hydrochloride (eye drops: $5 \mathrm{mg} / \mathrm{mL}$, administered into the conjunctival sac at $10 \mathrm{~min}$ intervals, followed by a single intraconjunctival application of lignocaine gel (lignocainum $20 \mathrm{mg} / \mathrm{mL}$ )). Ten minutes after anesthesia, the surgical field (protective apparatus of the eye and periorbital skin) was disinfected with $5 \%$ povidone iodine.

A 27G sutureless vitrectomy system (DORC, Zuidland, the Netherlands) was used to perform 3 typical direct transconjunctival sclerectomies located $3.5 \mathrm{~mm}$ from the corneal limbus in the lower temporal, upper temporal and upper nasal quadrants, respectively, in 3 patients. The use of vented gas-forced infusion during the procedure guaranteed excellent control of the intraoperative intraocular pressure (IOP). ${ }^{2}$ Patients with vitreomacular traction syndrome and diabetic maculopathy were subjected to internal limiting membrane peeling with reusable microforceps. Adjuvant panretinal photocoagulation with $27 \mathrm{G}$ curved stepped laser probes was performed in the female patient with proliferative diabetic retinopathy, along with fluid-air exchange due to diabetic maculopathy. The final stage of 27G PPV comprised detailed examination of the peripheral retina up to the ora serrata for any potential iatrogenic intraoperative retinal injuries (iatrogenic holes, choroidal detachment, retinal detachment/ retinoschisis, etc.); no such pathologies were identified.

Subsequently, the trocars were removed. None of the patients required placement of conjunctival and scleral sutures. Ofloxacin drops were routinely administered into the conjunctival sac along with hydrocortisone acetate and oxytetracycline hydrochloride.

The surgery time was $35 \mathrm{~min}$ for vitreomacular traction syndrome, $15 \mathrm{~min}$ for asteroid hyalosis and $25 \mathrm{~min}$ for the removal of epiretinal membrane. The severity of intraoperative and postoperative pain was determined using the ten grade Visual Analogue Scale (VAS), with 0 corresponding to a lack of pain and 10 corresponding to the most severe, unbearable pain. The severity of pain was assessed 4 times: immediately after PPV as well as $2 \mathrm{~h}$, $4 \mathrm{~h}$ and $6 \mathrm{~h}$ after the surgery.

\section{Results}

The clinical characteristics of the patients are presented in Table 1. No patients required additional (periocular, 
subconjunctival or systemic) analgesia, either intraor postoperatively ( $2 \mathrm{~h}, 4 \mathrm{~h}$ and $6 \mathrm{~h}$ after the surgery). In all cases, the severity of pain corresponded to grade 0 (i.e., lack of pain and discomfort).

All patients showed postoperative improvement in visual acuity (Table 2). No decrease in IOP below $10 \mathrm{~mm} \mathrm{Hg}$ was documented on postoperative day 1 . Furthermore, no postoperative complications were recorded during the sixmonth follow-up, and evident improvement of the anatomical status was confirmed using OCT in all cases (Fig. 1).

\section{Discussion}

The implementation of sutureless transconjunctival vitrectomy reflects the advances in vitreoretinal surgery over the last 20 years. However, after initial euphoria, a number of papers pointing out the technical weaknesses of early PPV systems were published. Due to their many flaws (e.g., poor performance of the stripper, too low efficiency of infusion, excessive flexibility), the initially utilized 25G instruments were replaced by $23 \mathrm{G}$ devices. The latter were considered the "gold standard" as they enabled sutureless procedures while eliminating all the flaws inherent

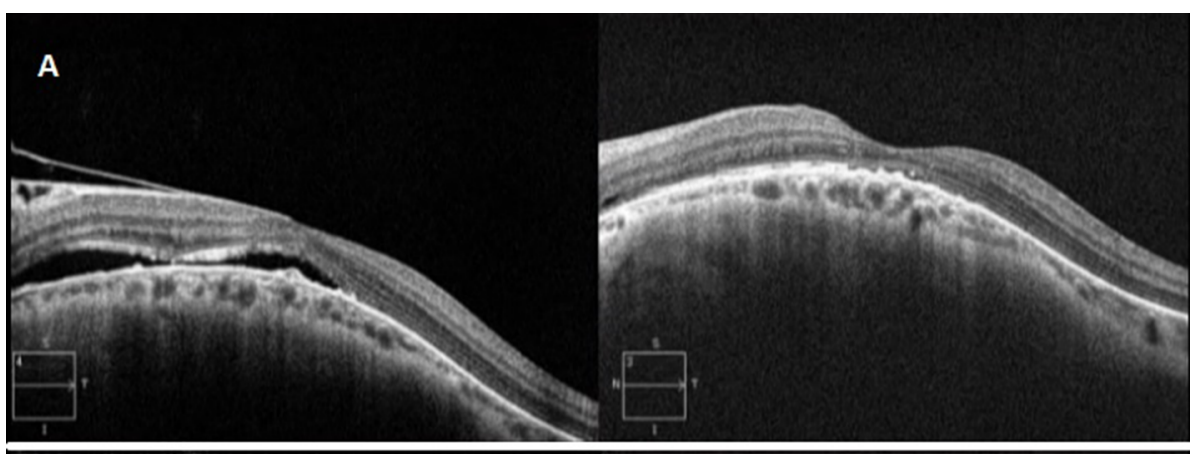

Fig. 1. A. Preoperative optical coherence tomography (OCT) scan showing vitreomacular traction (in a patient with high myopia) (left). Postoperative OCT revealing complete release of traction with reduction in central foveal thickness (right); B. Preoperative OCT scan in a patient with vitreoretinal traction syndrome (left). Postoperative OCT with complete release of traction (right)

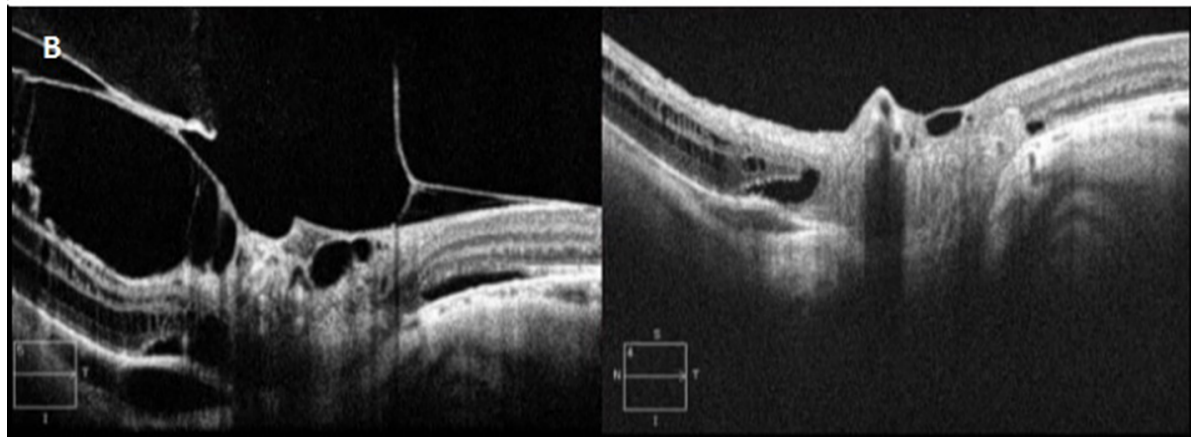

Table 1. Patient characteristics

\begin{tabular}{|l|c|c|c|c|}
\hline \multicolumn{1}{|c|}{ Patient } & Condition & Age & Gender & $\begin{array}{c}\text { Pain } \\
\text { score }\end{array}$ \\
\hline RA & $\begin{array}{c}\text { Procedure } \\
\text { status post panretinal photocoagulation OU }\end{array}$ & 28 & F & $\begin{array}{c}\text { PPV + ILM peeling + } \\
\text { endolaser }\end{array}$ \\
\hline SM & $\begin{array}{c}\text { vitreous opacities OU } \\
\text { pseudophakia OU } \\
\text { glaucoma OU }\end{array}$ & 82 & F & PPV \\
\hline GJ & $\begin{array}{c}\text { vitreomacular traction syndrome OS } \\
\text { high myopia OS }\end{array}$ & F & PPV + ILM peeling \\
\hline
\end{tabular}

OU - both eyes; OS - left eye; PPV - pars plana vitrectomy; LLM - inner limiting membrane.

Table 2. Preoperative and postoperative intraocular pressure (IOP) with best corrected visual acuities (BCVA) at 1 week and 6 months after surgery

\begin{tabular}{|l|c|c|c|c|c|}
\hline Patient & $\begin{array}{c}\text { BCVA preoperatively } \\
\text { (Snellen chart) }\end{array}$ & $\begin{array}{c}\text { BCVA at 1 week post } \\
\text { surgery } \\
\text { (Snellen chart) }\end{array}$ & $\begin{array}{c}\text { BCVA at 6 months post } \\
\text { surgery } \\
\text { (Snellen chart) }\end{array}$ & Preoperative IOP & $\begin{array}{c}\text { Postoperative } \\
\text { IOP (day 1) }\end{array}$ \\
\hline RA & FC 1 m & FC 1,5 m & FC 3 m & $18.0 \mathrm{~mm} \mathrm{Hg}$ & $15.0 \mathrm{~mm} \mathrm{Hg}$ \\
\hline SM & 0.3 & 0.5 & 0.6 & $17.0 \mathrm{~mm} \mathrm{Hg}$ & $19.0 \mathrm{~mm} \mathrm{Hg}$ \\
\hline GJ & 0.1 & 0.2 & 0.3 & $15.0 \mathrm{~mm} \mathrm{Hg}$ & $10.0 \mathrm{~mm} \mathrm{Hg}$ \\
\hline
\end{tabular}

FC - finger counting. 
to $25 \mathrm{G}$ microinstruments. However, in 2007, Oshima et al. introduced a novel $27 \mathrm{G}$ endoillumination system. ${ }^{6}$ Shortly thereafter, Sakaguchi et al. reported their experiences with $27 \mathrm{G}$ nonvitrectomizing vitreous surgery in a patient with epiretinal membrane. ${ }^{7}$

The paucity of papers documenting the application of these least invasive vitrectomy systems reflects the persisting opinions of vitreoretinal surgeons about the limited usefulness of $27 \mathrm{G}$ microinstruments. After familiarizing ourselves with the experiences of other authors, ${ }^{8-10}$ we decided to conduct $27 \mathrm{G}$ procedures in a carefully selected cohort of patients at our center. We present the technical possibilities of conducting PPV using the instruments with such small diameters. Our patients required relatively small surgical interventions: internal limiting membrane peeling, removal of the epiretinal membrane, and local vitreoretinal tractions or vitreous body with floaters and intravitreal hemorrhage. The procedure resulted in satisfactory anatomical outcomes and improved visual acuity in all cases. None of the patients required placing sutures on conjunctival and scleral wounds; furthermore, we did not record any cases of postoperative hypotony. Finally, no reoperations with microinstruments larger than $27 \mathrm{G}$ were required.

The relatively poor performance of vitrectomy and infusion systems represents the most significant challenge during 27G PPV. Oshima et al. documented the technical parameters of a $27 \mathrm{G}$ device, which are characterized by a slightly lower flow cut (62\%) and aspiration rates (80\%) than a $25 \mathrm{G}$ vitrectomy system. ${ }^{6}$ However, the duty cycle of the cutter turned out to be better than in the case of larger instruments, and vented gas-forced infusion at $30 \mathrm{~mm} \mathrm{Hg}$ enabled the maintenance of optimal intraoperative IOP. The technical possibilities of the abovementioned system (aspiration, infusion and striper efficiencies) and characteristics of individual microinstruments guaranteed fast and flawless outcomes of all planned intraoperative manipulations (including the access to the peripheral part of the eye).

None of our patients who qualified for 27G PPV required any complicated intraoperative manipulation, and the lack of conjunctival and scleral suture placement was reflected by a marked shortening of the surgical time. Therefore, we decided to perform the procedure solely under local topical anesthesia, augmented with lignocaine gel. Similar experiences with $25 \mathrm{G}$ vitrectomy under local anesthesia were previously reported by Raju et al. ${ }^{11}$ The use of topical anesthesia, combined with infiltration anesthesia in the areas of planned sclerectomies, turned out to be sufficient for a complete elimination of pain, both during the surgeries and postoperatively. Chakraborty et al. used a similar protocol of anesthesia for successful repair of ruptured globes. ${ }^{12}$ It should be noted that the use of local anesthesia does not represent a novel approach to PPV. As early as 1999, Yepez et al. reported successful use of sedation and local anesthesia for 20G PPV. However, the patients of that study reported mild (grade 2) pain, especially during cauterization of the scleral vessels, sclerectomy, and placement of scleral and conjunctival sutures. ${ }^{13}$ The use of modern sutureless vitrectomy systems seems to considerably limit the extent of scleral trauma (due to the protection of scleral ports with cannulas), and markedly attenuates or even completely eliminates pain. The minimal size of the ports is another advantage of the $27 \mathrm{G}$ systems used in our patients. It markedly limited the extent of scleral trauma compared with other available microinstruments. In addition, the lack of cauterization of the scleral vascular bed and completely sutureless nature of the procedure markedly attenuated the pain experienced by the patients. The use of topical anesthesia and intraconjunctival administration of lignocaine gel seem to be optimal choices in terms of patient comfort. A protocol for anesthesia allowing a completely painless procedure is vital from the patient's perspective. Due to retained eye movements during the procedure, a proper qualification of patients remains a crucial determinant of a successful surgery.

\section{Limitations}

The limitations of this study include the relatively small sample of patients. Further studies with larger samples and more comprehensive evaluations are warranted.

\section{Conclusions}

Our findings suggest that the 27G PPV system is a safe and effective treatment for various vitreoretinal diseases. Even though $27 \mathrm{G}$ surgery is not widely performed at present, it may soon become a standard of management for patients who require the so-called simple vitreoretinal procedures due to its unquestioned advantages, minimal ocular trauma and possibility of topical anesthesia.

\section{ORCID iDs}

Joanna Adamiec-Mroczek (D) https://orcid.org/0000-0002-6804-358X

\section{References}

1. Pollack JS, Sabherwal N. Small gauge vitrectomy: Operative techniques. Curr Opin Ophthalmol. 2019;30(3):159-164. doi:10.1097/ICU.00 00000000000568

2. Khanduja S, Kakkar A, Majumdar S, Vohra R, Garg S. Small gauge vitrectomy: Recent update. Oman J Ophthalmol. 2013;6(1):3-11. doi:10. 4103/0974-620X.111893

3. Shields RA, Ludwig CA, Powers MA, Tran EMT, Smith SJ, Moshfeghi DM. Postoperative adverse events, interventions, and the utility of routine follow-up after 23-, 25-, and 27-gauge pars plana vitrectomy. Asia Pac J Ophthalmol (Phila). 2019;8(1):36-42. doi:10.22608/APO. 2018398

4. Oshima Y, Wakabayashi T, Sato T, Ohji M, Tano Y. A 27-gauge instrument system for transconjunctival sutureless microincision vitrectomy surgery. Ophthalmology. 2010;117(1):93-102.e2. doi:10.1016/j. ophtha.2009.06.043

5. Lin X, Apple D, Hu J, Tewari A. Advancements of vitreoretinal surgical machines. Curr Opin Ophthalmol. 2017;28(3):242-245. doi:10.1097/ ICU.0000000000000369 
6. Oshima Y, Awh CC, Tano Y. Self-retaining 27-gauge transconjunctival chandelier endoillumination for panoramic viewing during vitreous surgery. Am J Ophthalmol. 2007;143(1):166-167. doi:10.1016/j. ajo.2006.07.051

7. Sakaguchi H, Oshima Y, Tano Y. 27-gauge transconjunctival nonvitrectomizing vitreous surgery for epiretinal membrane removal. Retina. 2007;27(8):1131-1132. doi:10.1097/IAE.0b013e31805931c0

8. Mori R, Naruse S, Shimada H. Comparative study of 27-gauge and 25-gauge vitrectomy performed as day surgery. Int Ophthalmol. 2018;38(4):1575-1582. doi:10.1007/s10792-017-0625-0

9. Li J, Liu SM, Dong WT, et al. Outcomes of transconjunctival sutureless 27-gauge vitrectomy for vitreoretinal diseases. Int JOphthalmol. 2018;11(3):408-415. doi:10.18240/ijo.2018.03.10
10. Masri I, Steel DH. Outcomes of 27 gauge microincision vitrectomy surgery for posterior segment disease. Am J Ophthalmol. 2016;164: 147-148. doi:10.1016/j.ajo.2016.01.012

11. Raju B, Raju NS, Raju AS. 25 gauge vitrectomy under topical anesthesia: A pilot study. Indian J Ophthalmol. 2006;54(3):185-188. doi:10. 4103/0301-4738.27070

12. Chakraborty A, Bandyopadhyay SK, Mukhopadhyay S. Regional anaesthesia for surgical repair in selected open globe injuries in adults. Saudi J Ophthalmol. 2013;27(1):37-40. doi:10.1016/j.sjopt.2011.12.002

13. Yepez J, Cedeño de Yepez J, Arevalo JF. Topical anesthesia in posterior vitrectomy. Retina. 2000;20(1):41-45. doi:10.1097/00006982200001000-00008 